\title{
Occurrence and characteristics of polybrominated dibenzo-p-dioxins and dibenzofurans in stack gas emissions from industrial thermal processes
}

\author{
Bing Du ${ }^{\mathrm{a}, \mathrm{b}}$, Minghui Zheng ${ }^{\mathrm{a}, *}$, Honghai Tian ${ }^{\mathrm{b}}$, Aimin Liu ${ }^{\mathrm{b}}$, Yeru Huang ${ }^{\mathrm{b}}$, Lingling Li ${ }^{\mathrm{b}}, \mathrm{Te}^{\mathrm{Ba}}{ }^{\mathrm{a}}, \mathrm{Nan} \mathrm{Li}^{\mathrm{b}}$, \\ Yue Ren ${ }^{b}$, Yuwu Li ${ }^{\mathrm{b}}$, Shuping Dong ${ }^{\mathrm{b}}$, Guijin $\mathrm{Su}^{\mathrm{a}}$ \\ a State Key Laboratory of Environmental Chemistry and Ecotoxicology, Research Center for Eco-Environmental Sciences, Chinese Academy of Sciences, P.O. Box 2871, Beijing \\ 100085, China \\ ${ }^{\mathrm{b}}$ State Environmental Protection Key Laboratory of Dioxin Pollution, National Research Center for Environmental Analysis and Measurement, Beijing 100029, China
}

\section{A R T I C L E I N F O}

\section{Article history:}

Received 7 March 2010

Received in revised form 26 April 2010

Accepted 26 May 2010

Available online 19 June 2010

\section{Keywords:}

Stack gas emissions

PBDD/F

Industrial thermal processes

Source identification

\begin{abstract}
A B S T R A C T
The occurrence and characteristics of 2,3,7,8-substituted polybrominated and polychlorinated dibenzo-pdioxins and dibenzofurans (PBDD/F and PCDD/F) from various combustion and metallurgic industrial thermal processes were investigated. $\mathrm{PBDD} / \mathrm{F}$ levels from metallurgic processes (TEQ ${ }^{*}$ concentrations from 0.14 to $1.5 \mathrm{ng} \mathrm{N} \mathrm{m}^{-3}$, mass concentrations from 0.56 to $5.8 \mathrm{ng} \mathrm{N} \mathrm{m}^{-3}$ ) were markedly higher than those from combustion processes (TEQ ${ }^{*}$ concentrations from 0.010 to $0.054 \mathrm{ng} \mathrm{N} \mathrm{m}^{-3}$, mass concentrations from 0.025 to $0.15 \mathrm{ng} \mathrm{N} \mathrm{m}^{-3}$ ). This indicated that metallurgic processes could be important sources of PBDD/F. Consequently, more attention should be paid to the metallurgical emission sources in addition to combustion of brominated flame retardants (BFRs) and related products. Specific isomeric patterns for PCDD/F from various industrial sources were highly consistent, while PBDD/F patterns were not. This revealed that PCDD/F might form through a common mechanism such as de novo synthesis mechanism, while PBDD/F might form by different mechanisms in thermal processes such as precursor mechanisms. Finally, an approach to identify the PBDD/F sources in ambient air by using the PBDD/F to PCDD/F ratio was developed.
\end{abstract}

(c) 2010 Elsevier Ltd. All rights reserved.

\section{Introduction}

Polychlorinated dibenzo-p-dioxins and dibenzofurans (PCDD/F) have been studied for several decades and are well-known as unintentionally generated persistent organic pollutants (POPs), which pose serious health and environmental risks on a global scale (UNEP, 2005). Polybrominated dibenzo-p-dioxins and dibenzofurans (PBDD/F) have similar properties and effects to $\mathrm{PCDD} / \mathrm{F}$, as they are structural analogs with all the chlorine atoms substituted by bromine atoms (Birnbaum et al., 2003; Olsman et al., 2007). According to previous research, $\mathrm{PBDD} / \mathrm{F}$ appears to have high molecular weights, low vapor pressures, and high lipophilicity (WHO, 1998; D’Silva et al., 2004; Van den Berg et al., 2006). They have been found in various matrices such as air, sediments, marine products, and human adipose samples (Choi et al., 2003; Malmvarn et al., 2005; Wang et al., 2007; Li et al., 2008). In comparison to $\mathrm{PCDD} / \mathrm{F}$, analytical difficulties mean that little is known about the occurrence, levels and characteristics of PBDD/F in various environmental matrices and their emission sources (Hagberg, 2008).

Under the Stockholm Convention on POPs, national inventories and emission factors have been investigated for PCDD/F in many

\footnotetext{
* Corresponding author. Tel.: +86 10 62849172; fax: +86 1062923563 .

E-mail address: zhengmh@rcees.ac.cn (M. Zheng).
}

countries and regions. These have been used to estimate PCDD/F release from various industrial sources and notable reductions in emissions have been observed as a result of using the best available techniques and best environmental practices (BAT/BEP) (Chen, 2004; Qua $\beta$ et al., 2004; Cleverly et al., 2006; Fiedler, 2007; Ba et al., 2009; Liu et al., 2009). In recent years, extensive use of brominated flame retardants (BFRs), especially for polybrominated diphenyl ethers (PBDEs) (D'Silva et al., 2004), has provided more available bromine and increased the chance of $\mathrm{PBDD} / \mathrm{F}$ formation in both natural environment and industrial processes. Consequently, PBDD/F as well as PCDD/F should be the focus of attention. While limited reports have suggested that specific PBDD/F congeners can be naturally biosynthesized (Haglund et al., 2007), many laboratories and pilot-scale studies have verified considerable amounts of $\mathrm{PBDD} / \mathrm{F}$ are produced during manufacturing, processing, and combustion related to BFRs (Ebert and Bahadir, 2003; Balabanovich et al., 2005; Evans and Dellinger, 2005; Hanari et al., 2006). Weber and Kuch (2003) summarized the main categories of thermal processes that release $\mathrm{PBDD} / \mathrm{F}$ into the environment, and suggested that PBDD/F might share a similar de novo or precursor mechanism as PCDD/F (Everaert and Baeyens, 2002). However, there is little published data for large scale industrial thermal processes, which are the most important PCDD/F sources listed in the United Nations Environment Program (UNEP) toolkits (2005). 
In this study, various facilities involving both combustion and metallurgical processes were selected to evaluate potential PBDD/F sources. These processes included combustion processes involved in MWIs, IWIs and crematories, as well as metallurgical processes including iron ore sinter (SNT) plants, electric arc furnaces (EAF) for steel, and secondary nonferrous production. The sampling and analytical methods used throughout this study were identical so that data from the different processes was comparable. The occurrences and characteristics of PBDD/F and PCDD/F in the stack flue gases of the investigated facilities are presented and compared. The PBDD/F to PCDD/F ratios from various sources are reported and may provide a useful tool to identify PBDD/F sources in ambient air, and allow comparison to ratios from different sites reported in other studies.

\section{Materials and methods}

\subsection{Sampling}

Facilities chosen for the investigation represent the various industrial processes in China, and the notations for these are listed in Table 1. Samples were collected from these facilities from November 2007 to April 2008. The facilities included incinerators (HWI and MWI) and crematories (CreP and CreT) to represent combustion processes, an iron ore sinter (SNT) plant, an EAF for steel production plant, and some secondary copper ( $\mathrm{SCu}$ ), secondary aluminum (SAl), secondary lead ( $\mathrm{SPb})$, and secondary zinc (SZn), smelters to represent metallurgical processes. Most of selected facilities were equipped with dust control units except for the two crematories.

The operational parameters, including feedstock and temperature in the key operation units for the incineration and metallurgical processes are listed in Tables S1-S3 in Supplementary material.

For each facility, three to five flue gas samples were isokinetically collected from the stacks as per Chinese national guidelines for PCDD/F emission analysis (HJ77.2) (MEP, 2008). A total of 33 samples were collected, and the details for the samples collected at each facility are included in Table S1. Samples were collected using the ISO BASIC System (Tecora Corp. Italy), which is composed

Table 1

Characteristics of investigated sintering facilities.

\begin{tabular}{|c|c|c|c|c|}
\hline Emission sources & Denotation & $\begin{array}{l}\text { Operation } \\
\text { type }\end{array}$ & Capacity & $\begin{array}{l}\text { Dust } \\
\text { control } \\
\text { unit }\end{array}$ \\
\hline $\begin{array}{l}\text { Hazardous waste } \\
\text { incinerator }\end{array}$ & HWI & Continuous & $15 \mathrm{~T} / \mathrm{d}$ & $\mathrm{BF}^{\mathrm{a}}$ \\
\hline $\begin{array}{l}\text { Municipal solid waste } \\
\text { incinerator }\end{array}$ & MWI & Continuous & $150 \mathrm{~T} / \mathrm{d}$ & $\mathrm{ESP}^{\mathrm{b}}$ \\
\hline Crematory 1 & CreP & Intermittent & $\begin{array}{l}1 \text { Body/ } \\
\text { batch }\end{array}$ & NA \\
\hline Crematory 2 & CreT & Intermittent & $\begin{array}{l}1 \text { Body/ } \\
\text { batch }\end{array}$ & NA \\
\hline Sinter facilities & SNT & Continuous & $300 \mathrm{~T} / \mathrm{h}$ & ESP \\
\hline $\begin{array}{l}\text { Electric arc furnace for } \\
\text { steel making }\end{array}$ & $\mathrm{EAF}$ & Intermittent & $\begin{array}{l}160 \mathrm{~T} / \\
\text { batch }\end{array}$ & $\mathrm{BF}$ \\
\hline Secondary lead smelter & $\mathrm{SPb}$ & Intermittent & $\begin{array}{l}6 \mathrm{~T} / \\
\text { batch }\end{array}$ & $\mathrm{BF}$ \\
\hline $\begin{array}{l}\text { Secondary aluminum } \\
\text { smelter }\end{array}$ & SAl & Intermittent & $\begin{array}{l}5 \mathrm{~T} / \\
\text { batch }\end{array}$ & $\mathrm{BF}$ \\
\hline $\begin{array}{l}\text { Secondary copper } \\
\text { smelter }\end{array}$ & $\mathrm{SCu}$ & Intermittent & $\begin{array}{l}95 \mathrm{~T} / \\
\text { batch }\end{array}$ & $W^{c}$ \\
\hline Secondary zinc smelter & SZn & Intermittent & $\begin{array}{l}4 \mathrm{~T} / \\
\text { batch }\end{array}$ & WS \\
\hline
\end{tabular}

\footnotetext{
NA not available.

a BF: bag filter.

b ESP: electrostatic precipitator.

c WS: wet scrubber.
}

of a heated titanium lined sampling probe, a quartz-filter unit, a water-cooled condenser, and a XAD-2 sorbent trap. ${ }^{37} \mathrm{Cl}_{4}-2,3,7,8$ TCDD was spiked into the resin as a standard to evaluate the sampling efficiency. The gaseous phase sample was collected by the $\mathrm{XAD}-2$ resin and condensed water, while the particulate phase was collected by the quartz-fiber filter. After sampling, the probe liner was washed with acetone and the washing solution retained for analysis. The analytical sample consisted of the filter, XAD-2 resin, and concentrated water and solvent washings from the probe of the sampling train. To ensure that the collected samples were free of contamination, field blanks were also taken during sampling. All samples were stored in darkness and taken to the laboratory within 1 week.

\subsection{Analytical procedures}

Analysis of PBDD/F and PCDD/F followed the HJ/77.2 standard (MEP, 2008). Briefly, for the flue gas samples, the filter was air dried and treated with $\mathrm{HCl}$ solution $(2 \mathrm{M})$. The resultant washes were combined with washes from the probe and then extracted with dichloromethane (DCM). The filter and XAD-2 resin were Soxhlet-Dean stark extracted with $300 \mathrm{~mL}$ of toluene (pesticidegrade) for $24 \mathrm{~h}$ and spiked with ${ }^{13} \mathrm{C}$-labelled isotope standards (EPA 1613 LCS, Wellington Laboratories Inc. and EDF 5382, Cambridge Isotope Laboratories, Inc.) after air-drying. The toluene and DCM extracts were combined and exchanged into hexane solvent. Then, the hexane extracts were concentrated for $\mathrm{H}_{2} \mathrm{SO}_{4}$ purification.

After $\mathrm{H}_{2} \mathrm{SO}_{4}$ treatment, the extracts from the same sampling site were combined and concentrated using the following clean-up procedures.

The extracts were first applied to a multilayer silica column, and then concentrated and transferred to an active carbon impregnated silica column to separate $\mathrm{PBDD} / \mathrm{F}$ and $\mathrm{PCDD} / \mathrm{F}$ from $\mathrm{PCBs}$ and PBDEs. DCM/hexane solvent ( $25 \%$ by volume) and toluene were used to elute the column sequentially. The toluene fraction containing $\mathrm{PBDD} / \mathrm{F}$ and $\mathrm{PCDD} / \mathrm{F}$ congeners was collected and concentrated to $0.5 \mathrm{~mL}$ by rotary evaporation, and the final extracts were concentrated using a gentle nitrogen flow. After ${ }^{13} \mathrm{C}$-labelled standards had been added (EPA 1613 ISS, Wellington Laboratories Inc. and EDF 5383, Cambridge Isotope Laboratories, Inc.) the extracts were diluted to $50 \mu \mathrm{L}$ with decane and transferred to a PTFE sealed vial for instrument analysis.

PBDD/F and PCDD/F analysis was conducted by HRGC/HRMS on a Waters Autospec Ultima NT equipped with Agilent 6890 N. The mass spectrometer was operated in electron ionization mode at $35 \mathrm{eV}$ ionizing potential and 10000 resolution power (10\% peak valley definition). A DB5-HT column (30 m long, i.d. $0.25 \mathrm{~mm}$, film thickness $0.10 \mu \mathrm{m}$ ) was employed to separate the 2,3,7,8-substituted PBDD/F congeners, and a DB5-MS column (60 m long, i.d. $0.25 \mathrm{~mm}$, film thickness $0.25 \mu \mathrm{m}$ ) for the PCDD/F congeners. The injection volume was $1 \mu \mathrm{L}$.

2,3,7,8-Chlorine and bromine substituted congeners were accurately identified by the isotope dilution method. The other non2,3,7,8-PCDD/F and PBDD/Fs congeners were qualified by monitoring the two most abundant ions of the molecular ion clusters, and quantification was carried out using the ${ }^{13} \mathrm{C}$-labelled standards. The details for this method are included in the Supplementary material.

\subsection{Quality assurance and quality control}

Each sample was spiked with ${ }^{13} \mathrm{C}$-labelled standards of PCDD/F and $\mathrm{PBDD} / \mathrm{F}$ to evaluate the performance of the sampling and clean-up procedures. The details of this are included in Table S4 in Supplementary material. Briefly, the recovery for the sampling 
standards ranged from $114 \%$ to $127 \%$, while the mean recovery of the clean-up standards ranged from $75 \%$ to $89 \%$ for PCDD/F, from $78 \%$ to $101 \%$ for tetra to hexa brominated BDD/F. The mean precision and recovery (PAR) of the standards ranged from 63\% to $123 \%$ for PBDD/F congeners and 76-116\% for PCDD/F congeners.

\section{Results and discussion}

\section{1. $P C D D / F$ and $P B D D / F$ concentrations in the stack gas samples from the investigated facilities}

The mean values of 2,3,7,8-substituted PCDD/F and 2,3,7,8substituted PBDD/F from each facility investigated are shown in Table 2. For PCDD/F, the average I-TEQ concentrations ranged from 0.030 to $3.0 \mathrm{ng} \mathrm{N} \mathrm{m}^{-3}$ with the exception of the SCu and SZn facilities. The I-TEQ levels of PCDD/F at the SCu and SZn facilities were 24 and $120 \mathrm{ng} \mathrm{N} \mathrm{m}^{-3}$ respectively, corresponding to mass concentrations of 4300 and $960 \mathrm{ng} \mathrm{N} \mathrm{m}^{-3}$. For PBDD/F, only nine 2,3,7,8substituted PBDD/F of tetra to hexa brominated homologues are reported due to limitations in quantitative analysis for the hepta and octa brominated homologues.

The I-TEF scheme of PCDD/F is used for the corresponding congener PBDD/F as suggested by the World Health Organization (WHO) and other researchers (WHO, 1998; Li et al., 2007) to allow TEQ calculation and the results for PBDD/F are expressed as "TEQ" in this study since there are no TEFs for 2,3,7,8-substituted PBDD/F that have international agreement. The detection limit is defined as a signal-to-noise ratio ( $\mathrm{S} / \mathrm{N}$, peak to peak definition) greater than three. The average TEQ ${ }^{*}$ concentrations related to combustion processes ranged from 0.010 to $0.054 \mathrm{ng} \mathrm{N} \mathrm{m}^{-3}$ for incinerators and crematories, and the corresponding mass concentrations ranged from 0.025 to $0.15 \mathrm{ng} \mathrm{N} \mathrm{m}^{-3}$. For the facilities involved in metallurgic processes the average $\mathrm{TEQ}^{*}$ concentrations ranged from 0.14 to $1.5 \mathrm{ng} \mathrm{N} \mathrm{m}^{-3}$, with corresponding mass concentrations from 0.56 to $5.8 \mathrm{ng} \mathrm{N} \mathrm{m}^{-3}$.

The ratios of $\mathrm{PBDD} / \mathrm{F}$ to $\mathrm{PCDD} / \mathrm{F}$ (referred to as $\mathrm{B} / \mathrm{C}$ ) were calculated on both TEQ and mass basis (Table 3 ). For emission sources, the $\mathrm{B} / \mathrm{C}$ TEQ ratios of HWI and MWI were 0.015 and 0.017 , while the corresponding $\mathrm{B} / \mathrm{C}$ mass ratios were 0.03 and 0.003 , respectively. For crematories, SZn and SCu facilities, the B/C TEQ ratios ranged from 0.001 to 0.016 and the $\mathrm{B} / \mathrm{C}$ mass ratios from 0.002 to 0.005 , which are similar to the results for HWIs and MWIs. For SNT, EAF, SPb and SAl facilities, B/C TEQ ratios ranged from 0.73 to 12 and $\mathrm{B} / \mathrm{C}$ mass ratios from 0.05 to 2.6. The PBDD/F levels from metallurgic process are clearly higher than those of combustion processes. Metallurgic facilities should be considered as important sources of PBDD/F also and more researches should focus on them in future.
Table 3

$\mathrm{B} / \mathrm{C}$ ratios in emission sources and ambient air.

\begin{tabular}{|c|c|c|c|c|c|c|}
\hline $\begin{array}{l}\text { Sources } \\
\text { (this } \\
\text { study) }\end{array}$ & Ambient ai & $(\mathrm{a}, \mathrm{b}, \mathrm{c})$ & & & & \\
\hline $\begin{array}{c}\text { Mass basis } \\
\text { (TEQ } \\
\text { basis) }\end{array}$ & $\begin{array}{l}\text { Mass basis } \\
\text { (TEQ } \\
\text { basis) }\end{array}$ & $G Y^{a}$ & $\mathrm{GZ}^{\mathrm{a}}$ & $\mathrm{SH}^{\mathrm{b}}$ & $\mathrm{TW}^{\mathrm{c}}$ & \\
\hline HWI & $\begin{array}{l}0.003 \\
(0.15)\end{array}$ & $\begin{array}{l}\text { BFR-related } \\
\text { sites }\end{array}$ & & & & $\begin{array}{l}0.15 \\
(0.91)\end{array}$ \\
\hline MWI & $\begin{array}{l}0.003 \\
(0.0017)\end{array}$ & & $\begin{array}{l}0.17 \\
(0.52)\end{array}$ & & & \\
\hline CreP & $\begin{array}{l}0.002 \\
(0.0077)\end{array}$ & & $\begin{array}{l}0.47 \\
(1.68)\end{array}$ & & & \\
\hline CreT & $\begin{array}{l}0.005 \\
(0.011)\end{array}$ & & $\begin{array}{l}0.27 \\
(1.07)\end{array}$ & & & \\
\hline $\mathrm{SCu}$ & $\begin{array}{l}0.001 \\
(0.016)\end{array}$ & $\begin{array}{l}\text { Major cities } \\
\text { and industrial } \\
\text { area }\end{array}$ & & & $\begin{array}{l}0.20 \\
(0.98)\end{array}$ & $\begin{array}{l}0.03 \\
(0.11)\end{array}$ \\
\hline SZn & $\begin{array}{l}0.006 \\
(0.0013)\end{array}$ & & & & & \\
\hline $\mathrm{SPb}$ & $0.05(1.4)$ & & & $\begin{array}{l}0.04 \\
(0.19)\end{array}$ & & \\
\hline SAl & $0.43(2.2)$ & & & $\begin{array}{l}0.14 \\
(0.47)\end{array}$ & & \\
\hline SNT & $0.51(0.73)$ & & & $\begin{array}{l}0.15 \\
(0.93)\end{array}$ & & \\
\hline EAF & $2.60(12)$ & & & & & \\
\hline
\end{tabular}

a $\mathrm{Li}$ et al. (2007).

b Li et al. (2008).

c Wang et al. (2008).

To investigate the influences of the contents of chlorine, bromine and transition metals on the formation of PBDD/F and PCDD/F, fly ash was collected from the metallurgical facilities and the contents of chlorine $(\mathrm{Cl})$ and bromine $(\mathrm{Br})$ were preliminarily qualified by Energy Dispersive X-ray (EDX) spectrometry. Neither the concentrations of PCDD/F or PBDD/F had a significant relationship with the total bromine or total chlorine contents or the bromine to chlorine ratios. Further studies are required to investigate the factors that affect the formation of $\mathrm{PBDD} / \mathrm{F}$ and $\mathrm{PCDD} / \mathrm{F}$ in metallurgical processes.

\section{2. $P C D D / F$ and $P B D D / F$ congener profiles of the investigated facilities}

Congener profiles (Fig. 1) of the 2,3,7,8-substituted PCDD/F and the 2,3,7,8-substituted PBDD/F species are represented as relative concentration of substituted congeners to the total substituted congener from each facility ( $n=17$ for PCDD/F and $n=9$ for $\mathrm{PBDD} / \mathrm{F}$ ). The homologue profiles of $\mathrm{PCDD} / \mathrm{F}$ and $\mathrm{PBDD} / \mathrm{F}$ are provided in Supplementary material (Figs. S1 and S2). The

Table 2

PBDD/F and PCDD/F concentrations from industrial thermal processes $\left(\mathrm{ng} \mathrm{N} \mathrm{m}^{-3}\right)$.

\begin{tabular}{|c|c|c|c|c|c|c|c|c|c|c|c|}
\hline & & HWI & MWI & CreP & CreT & SNT & EAF & $\mathrm{SPb}$ & SAl & $\mathrm{SCu}$ & SZn \\
\hline \multirow{10}{*}{$\mathrm{PBDD} / \mathrm{F}$} & $2,3,7,8-\mathrm{TBDF}$ & 0.039 & 0.010 & 0.027 & 0.018 & 0.52 & 0.16 & 0.36 & 0.12 & 1.8 & 1.6 \\
\hline & $1,2,3,7,8-\mathrm{PeBDF}$ & 0.055 & $<0.004^{\mathrm{a}}$ & 0.0068 & 0.014 & 0.88 & 0.28 & 0.46 & 0.070 & 0.24 & 0.78 \\
\hline & $2,3,4,7,8-\mathrm{PeBDF}$ & 0.014 & 0.0078 & 0.019 & $<0.004^{\mathrm{a}}$ & 0.20 & 0.070 & 0.23 & 0.067 & 0.11 & 1.6 \\
\hline & $1,2,3,4,7,8-\mathrm{HxBDF}$ & $<0.06^{\mathrm{a}}$ & $<0.003^{\mathrm{a}}$ & 0.013 & $<0.004^{\mathrm{a}}$ & 2.0 & 0.62 & 0.64 & 0.11 & 0.13 & 1.4 \\
\hline & $2,3,7,8-\mathrm{TBDD}$ & 0.015 & 0.0031 & 0.0052 & 0.0051 & 0.21 & 0.054 & 0.19 & 0.031 & 0.059 & 0.33 \\
\hline & 1,2,3,7,8-PeBDD & 0.025 & 0.0044 & 0.0044 & 0.0024 & 0.47 & 0.15 & 0.26 & 0.034 & 0.062 & 0.062 \\
\hline & $1,2,3,4 / 6,7,8-\mathrm{HxBDD}$ & $<0.06^{\mathrm{a}}$ & $<0.003^{\mathrm{a}}$ & $<0.01^{\mathrm{a}}$ & $<0.01^{\mathrm{a}}$ & 0.45 & 0.15 & 0.16 & 0.075 & 0.089 & 0.068 \\
\hline & $1,2,3,7,8,9-\mathrm{HxBDD}$ & $<0.09^{\mathrm{a}}$ & $<0.002^{\mathrm{a}}$ & $<0.01^{\mathrm{a}}$ & $<0.01^{\mathrm{a}}$ & 0.084 & 0.025 & $<0.02^{\mathrm{a}}$ & 0.056 & $<0.02^{\mathrm{a}}$ & $<0.05^{\mathrm{a}}$ \\
\hline & Mass & 0.15 & 0.025 & 0.075 & 0.040 & 4.8 & 1.5 & 2.3 & 0.56 & 2.5 & 5.8 \\
\hline & $\mathrm{TEQ}^{\mathrm{b}}$ & 0.054 & 0.012 & 0.023 & 0.010 & 1.1 & 0.35 & 0.70 & 0.14 & 0.39 & 1.5 \\
\hline \multirow[t]{2}{*}{$\mathrm{PCDD} / \mathrm{F}$} & Mass & 4.9 & 8.6 & 31 & 8.3 & 9.5 & 0.59 & 46 & 1.3 & 4300 & 960 \\
\hline & I-TEQ & 0.35 & 0.69 & 3.0 & 0.94 & 1.5 & 0.030 & 0.51 & 0.060 & 24 & 120 \\
\hline
\end{tabular}

a Below detection limit.

b Only recommended by WHO, not official. 

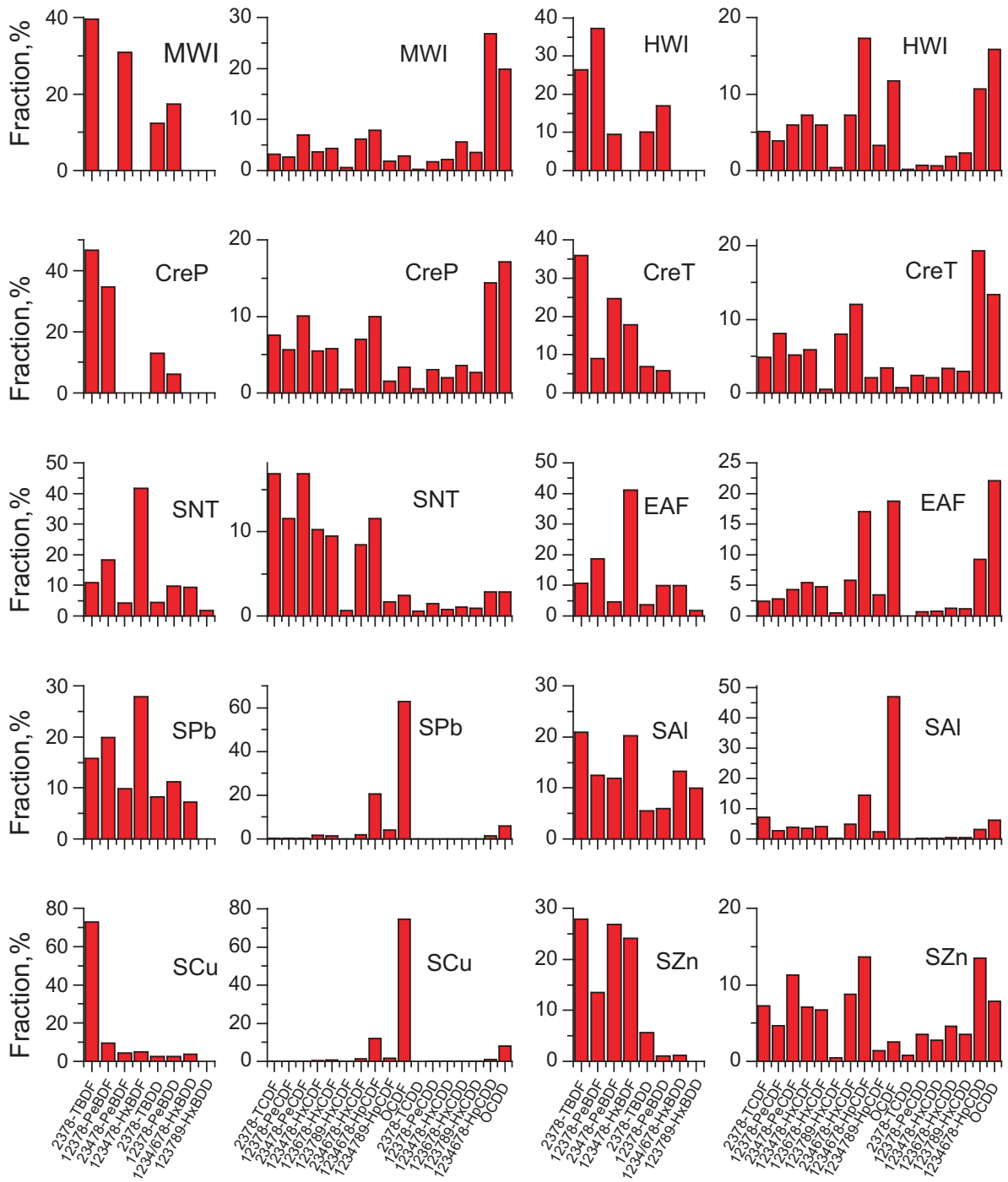

Fig. 1. Congener profiles of $\mathrm{PBDD} / \mathrm{F}$ and $\mathrm{PCDD} / \mathrm{F}$ by the ratio of $2,3,7,8$-substituted congeners to $\sum 2,3,7,8$-substituted congeners.

$1,2,3,4,6,7,8-\mathrm{HpCDF}$ and OCDF fractions predominated in SPb, SCu and SAl facilities and represented $26-47 \%$ of total $2,3,7,8$-substituted PCDD/F from waste incinerators, crematories, EAF and SZn. However, the profile of SNT was distinct from that of other facilities in that the concentration of tetra to hexa CDF accounted for more than $85 \%$ of the total 2,3,7,8-substituted PCDD/F. As for the homologue profiles, the PCDF/PCDD ratio in both combustion (an exception was in MWI) and metallurgic processes was greater than one (range from 1.4 to 17.2), which is an indicator of the de novo synthesis formation mechanism (Everaert and Baeyens, 2002).

The congener profiles of $\mathrm{PBDD} / \mathrm{F}$ were more variable. The 2,3,7,8-substituted HxBDD was below the limit of detection in all the samples from waste incinerators and crematories. The profiles of SNT and EAF were similar in that $1,2,3,4,7,8-\mathrm{HxBDF}$ accounted for $40 \%$ of the total tetra to hexa-substituted $\mathrm{BDD} / \mathrm{F}$ concentration. For SCu facilities, 2,3,7,8-TBDF dominated $72 \%$ of the total congeners. For homologue profiles, PBDF represented $78-99 \%$ of the total concentration of all investigated facilities. These patterns have also been observed in ambient air by other researchers (Hayakawa et al., 2004; Li et al., 2007, 2008).

To investigate the intrinsic patterns of PCDD/F formation, the congener pattern was calculated by dividing the concentration of each 2,3,7,8-substituted congener with that of corresponding homologues (same degree of chlorination). These results are presented in Fig. 2 (for PCDD/F) and Fig. 3 (for PBDD/F). For PCDD/F, the congener profiles from different facilities were highly consistent, which suggests a common mechanism, such as de novo synthesis mechanism, existed in thermal processes for both combustion and metallurgical processes. The ratio of 2,3,7,8substituted congeners to the corresponding homologue increased with the degree of chlorination, and the ratios of 2,3,7,8-substituted PCDD to corresponding total PCDD homologues were less than that of PCDF homologues at the same degree of chlorination. For PBDD/F, the congener profiles did not exhibit the same consistency as for $\mathrm{PCDD} / \mathrm{F}$, and this may imply different formation mechanisms.

Factor analysis (FA) classified the profiles of nine 2,3,7,8-substituted PBDD/F into two types (Fig. 3). The FA bi-plot revealed that factor 1 scores (first factor-axis) of the plot explained $68.4 \%$ of the total data variation for all congeners except for 1,2,3,7,8,9HxBDD. Factor 2 scores (secondary factor-axis) explained $17.3 \%$ of the total data variation for hexa-substituted congeners, especially for 1,2,3,7,8,9-HxBDD. It was apparent that the profiles could not be classified according to the different industrial thermal processes. In this study, the PBDD/F profiles in stack gases from SAl, SZn, MWI and crematories were classified as type 1, with PBDF ra- 


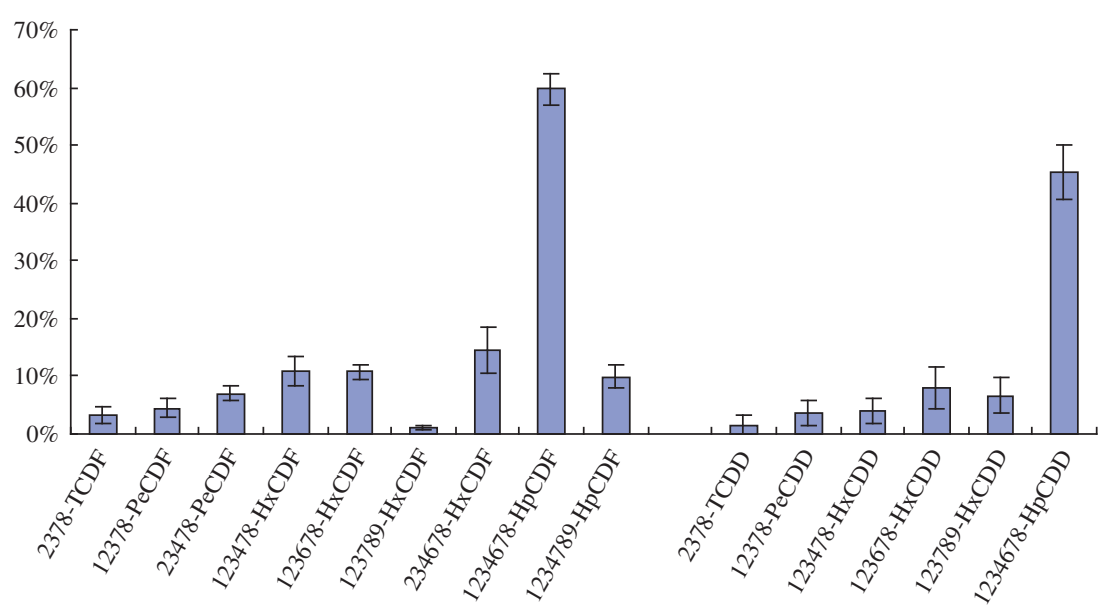

Fig. 2. Congener profiles of $\mathrm{PCDD} / \mathrm{F}$ by the ratio of 2,3,7,8-substituted congeners to corresponding homologues.

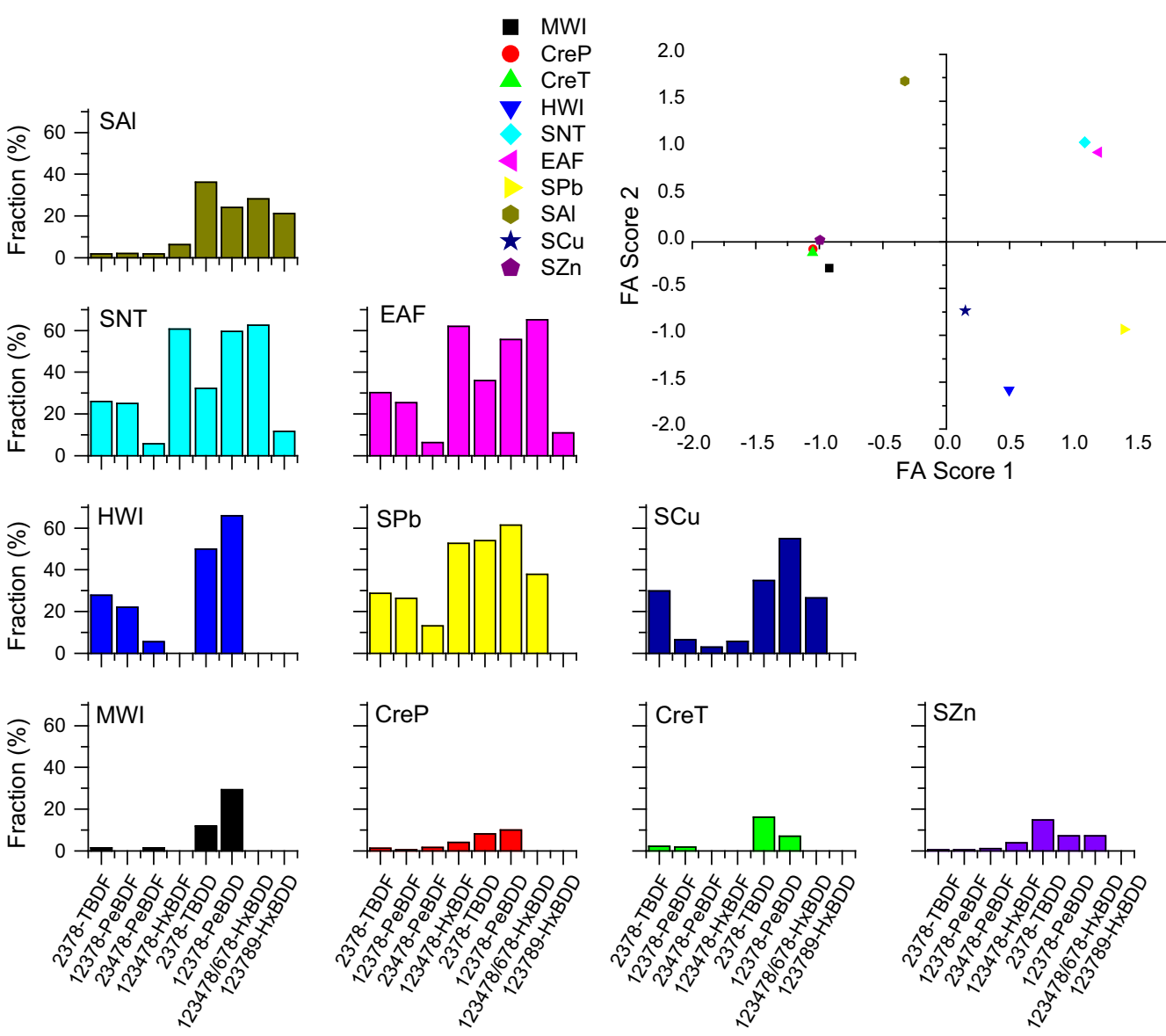

Fig. 3. Congener profiles of PBDD/F by the ratio of 2,3,7,8-substituted congeners to corresponding homologues classified by factor analysis.

tios ranging from $1 \%$ to $6 \%$ and PBDD ratios ranging from $7 \%$ to $29 \%$ for different bromination levels. The profiles from other facilities were classified as type 2, with PBDF ratios ranging from $3 \%$ to $61 \%$ and PBDD ratios ranging from $11 \%$ to $65 \%$ for different bromination levels. However, the ratio of 2,3,7,8-substituted PBDD to corresponding total PBDD homologues was higher than that of the PBDF homologues at the same degree of bromination, except for $1,2,3,7,8,9-\mathrm{HxBDD}$. These profile differences among PBDD/F might result from different formation pathways in the different processes compared with to the profile consistency observed with PCDD/F.
Further studies on PBDD/F formation mechanisms are required, especially for precursor mechanisms in different thermal processes. Some reports have shown that PBDEs are abundant in ash and scrap used as feedings at an aluminum smelter (Sinkkonen et al., 2003, 2004) and flue gas from an EAF (Odabasi et al., 2009), and these PBDEs may act as precursors in PBDD/F formation (Weber and Kuch, 2003).

Isomeric pattern analyses are widely used to determine PCDD/F formation mechanism from various sources. Differences between $\mathrm{PBDD} / \mathrm{F}$ and $\mathrm{PCDD} / \mathrm{F}$ patterns from certain sources have revealed 
different mechanisms for PBDD/F and PCDD/F formation. However, it is difficult to compare patterns from separate studies because differences or similarities apparent in isomeric patterns may be influenced by uncertainties from the sampling and analytical methodologies. Furthermore, isomeric pattern profiles calculated using different calculation methods could yield different modes from the same source. In this study, all data from the different thermal sources were obtained using the same methodology, thus avoiding analytical uncertainties. It is very interesting to observe that when a specific method is applied to describe isomeric patterns, PCDD/F patterns from various industrial sources are highly consistent, while PBDD/F patterns are not. The current study provides a basis on which to explore formation of PCDD/F and PBDD/F from various sources in future studies.

\subsection{Identification of pollution source of $P B D D / F$ in air}

Identifying the source of chemicals found in the environment is challenging. Since it has been shown that PBDD/F is generally formed with $\mathrm{PCDD} / \mathrm{F}$ in various industrial thermal processes and released into atmosphere, $\mathrm{B} / \mathrm{C}$ ratios from different emission sources might be specific and could be used to correlate environmental samples from ambient air with potential sources.

Pearson correlation analysis revealed that the logarithms of TEQ $\mathrm{B} / \mathrm{C}$ ratios significantly correlated with the logarithms of mass $\mathrm{B} / \mathrm{C}$ ratios from various thermal processes $(r=0.932, p<0.001$, regression coefficient $=0.908$ ), as did the $\mathrm{B} / \mathrm{C}$ ratios from ambient air $(r=0.995, p<0.001$, regression coefficient $=1.009)$. It appears that either TEQ $\mathrm{B} / \mathrm{C}$ ratios or mass $\mathrm{B} / \mathrm{C}$ ratios could be used as an indicator to identify the PBDD/F sources in ambient air, as the $\mathrm{B} / \mathrm{C}$ ratios vary greatly from different emission sources.

The relationship between the $\mathrm{B} / \mathrm{C}$ ratios of sources and those in ambient air might help to identity PBDD/F sources in ambient air. For this purpose, the limited literature data available on the levels of PCDD/F and PBDD/F in ambient air were compiled from areas including Guiyu, Shanghai, Guangzhou and some cities in Taiwan (Li et al., 2007, 2008; Wang et al., 2008). The B/C ratios were then re-calculated in this study. Some of the sampling sites from Guiyu, and a science park in Taiwan are classified as sites related to BFR and PBDEs use and disposal. $\mathrm{B} / \mathrm{C}$ ratios from these sites were high (0.15-0.47 for mass ratios and $0.52-1.68$ for TEQ ratios) and could be interpreted as BFR burning and use. Nonetheless, the considerable PBDD/F in ambient air reported for cities like Taiwan, Shanghai and Guangzhou are unlikely from the BFR-related sources mentioned above due to stringent local regulations, which prohibit open burning or disposal of wastes containing BFRs. The $\mathrm{B} / \mathrm{C}$ ratios, which ranged from 0.02 to 0.2 for mass ratios and from 0.09 to 0.98 for TEQ ratios, may be useful to determine the main contributors of $\mathrm{PBDD} / \mathrm{F}$ in these cities. The PBDD/F occurrence and characteristics in these cities should be interpreted as combined results from multiple sources. Since the highest $\mathrm{B} / \mathrm{C}$ ratios in ambient air were 0.2 on mass basis, it is unlikely that only incinerators contribute to PBDD/Fs emission as they had $\mathrm{B} / \mathrm{C}$ ratios of less than 0.03 in these cities. This suggests that besides incinerators there should be another PBDD/F emission sources with higher $\mathrm{B} / \mathrm{C}$ ratios. When compared with source $\mathrm{B} / \mathrm{C}$ ratios obtained in this study, ferrous metallurgical processes carried out at iron ore sinter and EAF facilities may also be the sources of PBDD/F in Guangzhou, Shanghai and industrial area in Taiwan besides incinerators. This correlates with the presence of local metallurgic industries. However, more detailed $\mathrm{B} / \mathrm{C}$ ratio ranges from various sources required for source identification are needed for further evaluation. Once the $\mathrm{B} / \mathrm{C}$ ratio in ambient air was known, the possible local sources could be screened out according to the comparison with the $\mathrm{B} / \mathrm{C}$ ratio ranges in different sources. Furthermore, the contribution from each pos- sible source might be estimated based on $\mathrm{B} / \mathrm{C}$ ratio and other characteristics of stack emission.

\section{Conclusions}

A primary investigation for PBDD/F emission from stack gas from industrial thermal processes in China were conducted in this study and the results showed that PBDD/F levels from metallurgic processes (TEQ ${ }^{*}$ concentrations from 0.14 to $1.5 \mathrm{ng} \mathrm{N} \mathrm{m}^{-3}$, mass concentrations from 0.56 to $5.8 \mathrm{ng} \mathrm{N} \mathrm{m}^{-3}$ ) were markedly higher than combustion processes (TEQ* concentrations from 0.010 to $0.054 \mathrm{ng} \mathrm{N} \mathrm{m}^{-3}$, mass concentrations from 0.025 to $0.15 \mathrm{ng} \mathrm{N} \mathrm{m}^{-3}$ ). The metallurgic processes could be important sources of $\mathrm{PBDD} / \mathrm{F}$ emission to atmosphere.

Isomeric pattern analyses revealed that $\mathrm{PCDD} / \mathrm{F}$ might form through a common mechanism such as de novo synthesis mechanism, while PBDD/F might form by different mechanisms such as precursor mechanisms in various thermal processes.

A source identification method for $\mathrm{PBDD} / \mathrm{F}$ in ambient air based on PBDD/F to PCDD/F ratio was developed and disclosed that ferrous metallurgical processes including iron ore sinter and EAF facilities might be the sources of PBDD/F in Guangzhou, Shanghai and industrial area in Taiwan besides incinerators.

\section{Acknowledgements}

This study was financially supported by the National Key Fundamental Research Project (Nos. 2009CB421602, 2009CB421606), the National High Technology Research and Development Program (No. 2006AA06Z403) and National Science Foundation of China (Nos. 20921603, 20977099).

\section{Appendix A. Supplementary material}

Supplementary material associated with this article can be found, in the online version, at doi:10.1016/j.chemosphere.2010. 05.044

\section{References}

Ba, T., Zheng, M., Zhang, B., et al., 2009. Estimation and characterization of PCDD/Fs and dioxin-like PCBs from secondary copper and aluminum metallurgies in China. Chemosphere 75, 1173-1178.

Balabanovich, A.I., Hornung, A., Luda, M.P., et al., 2005. Pyrolysis study of halogencontaining aromatics reflecting reactions with polypropylene in a post treatment decontamination process. Environ. Sci. Technol. 39, 5469-5474.

Birnbaum, L.S., Staskal, D.F., Diliberto, J.J., 2003. Health effects of polybrominated dibenzo-p-dioxins (PBDDs) and dibenzofurans (PBDFs). Environ. Int. 29, 855860.

Chen, C.-M., 2004. The emission inventory of PCDD/PCDF in Taiwan. Chemosphere 54, 1413-1420

Choi, J.W., Fujimaki, S., Kitamura, K., et al., 2003. Polybrominated dibenzo-p-dioxins, dibenzofurans, and diphenyl ethers in Japanese human adipose tissue. Environ. Sci. Technol. 37, 817-821.

Cleverly, D., Schweer, G., Lee, R., et al., 2006. An inventory of Sources and Environmental Releases of Dioxin-like Compounds in the United States for the Years 1987, 1995, and 2000. US EPA, Washington DC.

D’Silva, K., Fernandes, A., Rose, M., 2004. Brominated organic micropollutants igniting the flame retardant issue. Crit. Rev. Environ. Sci. Technol. 34, 141-207.

Ebert, J., Bahadir, M., 2003. Formation of PBDD/F from flame-retarded plastic materials under thermal stress. Environ. Int. 29, 711-716.

Evans, C.S., Dellinger, B., 2005. Formation of bromochlorodihenzo-p-dioxins and furans from the high-temperature pyrolysis of a 2-chlorophenol/2bromophenol mixture. Environ. Sci. Technol. 39, 7940-7948.

Everaert, K., Baeyens, J., 2002. The formation and emission of dioxins in large scale thermal processes. Chemosphere 46, 439-448.

Fiedler, H. 2007. National PCDD/F release inventories under the Stockholm Convention on persistent organic pollutants. Chemosphere 67, S96-S108.

Hagberg, J., 2008. Analysis of brominated dioxins and furans by high resolution gas chromatography/high resolution mass spectrometry. J. Chromatogr. A. 1216, 376-384.

Haglund, P., Malmvarn, A., Bergek, S., et al., 2007. Brominated dibenzo-p-dioxins: a new class of marine toxins? Environ. Sci. Technol. 41, 3069-3074. 
Hanari, N., Kannan, K., Miyake, Y., et al., 2006. Occurrence of polybrominated biphenyls, polybrominated dibenzo-p-dioxins, and polybrominated dibenzofurans as impurities in commercial polybrominated diphenyl ether mixtures. Environ. Sci. Technol. 40, 4400-4405.

Hayakawa, K., Takatsuki, H., Watanabe, I., et al., 2004. Polybrominated dipheny ethers (PBDEs), polybrominated dibenzo-p-dioxins/dibenzofurans (PBDD/Fs) and monobromo-polychlorinated dibenzo-p-dioxins/dibenzofurans (MoBPXDD/Fs) in the atmosphere and bulk deposition in Kyoto, Japan Chemosphere 57, 343-356.

Li, H.R., Yu, L.P., Sheng, G.Y., et al., 2007. Severe PCDD/F and PBDD/F pollution in air around an electronic waste dismantling area in China. Environ. Sci. Technol. 41, 5641-5646.

Li, H.R., Feng, H.L., Sheng, G.Y., et al., 2008. The PCDD/F and PBDD/F pollution in the ambient atmosphere of Shanghai, China. Chemosphere 70, 576-583.

Liu, G., Zheng, M., Liu, W., et al., 2009. Atmospheric emission of PCDD/Fs, PCBs, hexachlorobenzene, and pentachlorobenzene from the coking industry. Environ. Sci. Technol. 43, 9196-9201.

Malmvarn, A., Zebuhr, Y., Jensen, S., et al., 2005. Identification of polybrominated dibenzo-p-dioxins in blue mussels (mytillus edulis) from the baltic sea. Environ. Sci. Technol. 39, 8235-8242.

MEP, C., 2008. Ambient air and Waste gas Determination of Polychlorinated Dibenzo-p-dioxins(PCDDs) and Polychlorinated Dibenzofurans (PCDFs) Isotope Dilution HRGC-HRMS. Chinese Environmental Science Publisher.

Odabasi, M., Bayram, A., Elbir, T., et al., 2009. Electric arc furnaces for steel-making: hot spots for persistent organic pollutants. Environ. Sci. Technol. 43, 52055211.

Olsman, H., Engwall, M., Kammann, U., et al., 2007. Relative differences in aryl hydrocarbon receptor-mediated response for 18 polybrominated and mixed halogenated dibenzo-p-dioxins and -furans in cell lines from four different species. Environ. Toxicol. Chem. 26, 2448-2454.

Quaß, U., Fermann, M., Broker, G., 2004. The European dioxin air emission inventory project-final results. Chemosphere 54, 1319-1327.

Sinkkonen, S., Lahtipera, M., Vattulainen, A., et al., 2003. Analyses of known and new types of polyhalogenated aromatic substances in oven ash from recycled aluminium production. Chemosphere 52, 761-775.

Sinkkonen, S., Paasivirta, J., Lahtipera, M., et al., 2004. Screening of halogenated aromatic compounds in some raw material lots for an aluminium recycling plant. Environ. Int. 30, 363-366.

EP, U.N., 2005. Standardized Toolkit for Identification and Quantification of Dioxin and Furan Releases. Geneva, Switzerland.

Van den Berg, M., Birnbaum, L.S., Denison, M., et al., 2006. The 2005 World Health Organization reevaluation of human and mammalian toxic equivalency factors for dioxins and dioxin-like compounds. Toxicol. Sci. 93, 223-241.

Wang, D., Jiang, G., Cai, Z., 2007. Method development for the analysis of polybrominated dibenzo-p-dioxins, dibenzofurans and diphenyl ethers in sediment samples. Talanta 72, 668-674.

Wang, L.C., Tsai, C.H., Chang-Chien, G.P., et al., 2008. Characterization of polybrominated dibenzo-p-dioxins and dibenzofurans in different atmospheric environments. Environ. Sci. Technol. 42, 75-80.

Weber, R., Kuch, B., 2003. Relevance of bfrs and thermal conditions on the formation pathways of brominated and brominated-chlorinated dibenzodioxins and dibenzofurans. Environ. Int. 29, 699-710.

WHO, 1998. Environmental health criteria 205: Polybrominated dibenzo-p-dioxins and dibenzofurans. Geneva. 